\title{
THE DEVELOPMENT OF A TECHNOLOGY ROADMAP FOR FERROCHROME PRODUCERS
}

\author{
P.T. Letaba ${ }^{1 *} \&$ S. Zulu ${ }^{1}$
}

\section{ARTICLE INFO}

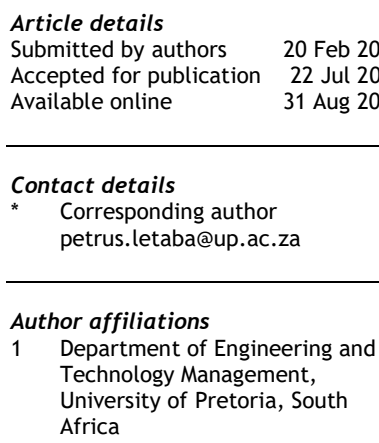

ORCID® identifiers

P.T. Letaba

http://orcid.org/0000-0001-5799-6679

S. Zulu

http://orcid.org/0000-0002-6201-2299

DOI

http://dx.doi.org/10.7166/32-2-2495

\section{ABSTRACT}

A 30-year technology roadmap for the South African ferrochrome industry is developed to address the increasing cost of electricity and competition from China. Research on possible technologies and their applicability in ferrochrome smelting is conducted, including Industry 4.0 technologies. The developed roadmap has three phases, with full-scale digitisation deferred to the second phase. The first phase addresses the stabilisation of the industry through the introduction of alternative energy sources. The last phase of the ferrochrome industry roadmap is sustainability, which builds on the successes of previous phases. This research contributes to methods the responsible introduction of Industry 4.0 technologies in industries with existing underlying challenges. The purpose of this article is to present a technology roadmap for ferrochrome producers in South Africa as chosen by the ferrochrome industry players.

\section{OPSOMMING}

'n Tegnologie padkaart vir die volgende 30 jaar in die Suid-Afrikaanse ferrochroom bedryf is ontwikkel om die toenemende koste van elektrisiteit en mededinging van Sjina aan te spreek. Navorsing oor moontlike tegnologieë (insluitend Industrie 4.0 tegnologieë) en hul toepassing in ferrochroom verwerking is van stapel gestuur. Die ontwikkelde padkaart het drie fases, met volskaalse digitalisering uitgestel tot die tweede fase. Die eerste fase adresseer die stabilisasie van die bedryf deur die aanneming van alternatiewe energiebronne. Die laaste fase fokus op volhoubaarheid van die vordering wat tydens die eerste twee fases behaal is. Hierdie navorsing dra by tot metodes vir die verantwoordelike bekendstelling van Industrie 4.0 tegnologieë in bedrywe met bestaande onderliggende uitdagings. Die doel van hierdie artikel is om die padkaart vir SuidAfrikaanse ferrochroom produsente voor te stel deur rolspelers binne-in die bedryf.

\section{INTRODUCTION AND BACKGROUND}

Ferrochrome is a ferroalloy product for the production of stainless steel. South Africa has large resources of ferrochrome ore, and is one of the world's leading producers of this metal. The production of ferroalloys started in the 1860s at low volumes. With the use of the crucible production technique, chromium or manganese mineral ore reacted with coal in reducing reaction using graphite crucibles at high temperatures to form high-carbon ferroalloy melt [1]. The French Terre Noire Company started producing ferromanganese in 1877, and showed that ferrosilicon, ferrovanadium, and ferrotitanium can be produced with a blast furnace; however, ferrochrome could not be produced with a similar process, owing to the high melting temperatures required for ferrochrome slag. Electric furnace smelting technology was introduced for achieving such high temperatures in the late 1800 s.

This study entails the development of a ferrochrome technology roadmap with the input of respondents involved with ferrochrome production. This roadmap is meant to address the challenges that the industry is experiencing, such as an exponential increase in the cost of producing ferrochrome owing to the increase in electricity, labour costs, and raw material prices. These economic factors have caused some ferrochrome producers to operate at a loss and to call for business rescue. 
The collapse of companies such as Nokia and Kodak, and the successes of companies such as Amazon, Google, and Apple can only be attributed to strategic technology foresight, or the lack thereof [2]. Technology roadmapping can help the South African ferrochrome industry to forecast the relevant technology for the future in ferrochrome production. Technology roadmapping is a tool that can be used in the ferrochrome industry for strategy planning in order for ferrochrome companies to compete in the global market. However, little work has been done on forecasting technology for the ferrochrome industry. While most companies are moving towards fourth industrial revolution technologies, currently very limited research is being done in the ferrochrome industry on the potential implementation of fourth industrial revolution technologies (e.g., digitisation). This study explores possible technologies for the future if the South African ferrochrome industry is to remain competitive in the global ferrochrome market.

The roadmap developed through this study addresses the South African ferrochrome industry's challenges through three phases: stabilisation, digitisation, and sustainability. A stabilisation phase avoids the typical hype about the fourth industrial revolution being an immediate solution to all the industry's challenges. This phase mainly addresses the issue of increasingly expensive electricity in South Africa by adopting various alternative energy sources. Digitisation is only introduced during the second phase of the roadmap, following the stabilisation of the industry. This sequencing, a key managerial and theoretical contribution of this study is important for the successful adoption of fourth industrial revolution technologies for any sector that has underlying issues. Sustainability is the last phase of the roadmap.

Technology roadmaps have considerable potential to reinforce the progress and implementation of nonsegregated strategic business, technology, and product plans, on the assumption that firms have the information, processes, and mechanisms to produce them [3]. Furthermore, roadmaps and their processes can contribute a way to strengthen a company's recognisability by expanding its planning horizons, together with recognising and assessing possible threats and opportunities in the business environment. Changes in technology, the effect of globalisation on business structures, and increased competition between firms and countries causes organisations and their corporate structures to focus more carefully on the management of innovation and technology [4].

This paper is structured as follows: Section 1 is the introduction and background; Section 2 focuses on the literature review; Section 3 presents the conceptual method for this study; the methodology is explained in Section 4; and Section 5 presents the results and the discussions. Finally, Section 6 summarises the conclusions and makes recommendations for future research.

\section{CRITIQUE OF CURRENT WORK AND THE FUTURE OF FERROCHROME PRODUCTION}

\subsection{The ferrochrome industry and current technologies}

Steenkamp, Bam, Ringdalen, Mushwana, Hockaday and Sithole [5] presented the challenges faced by ferrochrome producers in ferromanganese production in South Africa as the basis for needing a roadmap for South African ferromanganese producers. Their work identified six research opportunities, and through a workshop of the Second School on Manganese Ferro-alloy Production, obtained suggestions and ideas from industry experts on which opportunities could be prioritised. However, the study did not present an actual technology roadmap, but focussed on increasing ferromanganese production, which is not quite the same as ferrochrome production, but has similar applications and processes.

Van der Lingen and Paton [6] observed similar challenges faced by ferrochrome producers in South Africa: the increase in electricity prices, the selling price suppressed by China, the decline in beneficiation in South Africa, increased labour costs, and increased ore exports to China. Their study also investigated technological acquisition strategies for the South African ferrochrome industry. It surveyed all the South African ferrochrome producers for a preferred technological acquisition strategy (purchasing of technology, internal development of technology, collaboration with others), and found that the acquisition strategy changes with ferrochrome business cycles, and that technology mostly is developed for key processes and process support systems. The study did not provide a clear roadmap for ferrochrome producers to follow in order to sustain ferrochrome beneficiation and to increase the South African market share for ferrochrome.

New technologies for the production of ferrochrome are needed in order to sustain the industry. The technologies currently employed by South African ferrochrome smelters will not sustain the local industry in the coming 30 years as electricity, labour, and raw material prices continue to increase and as China increases its market share for ferrochrome and suppresses ferrochrome prices. There is a decrease in the beneficiation of ferrochrome, and that is negatively affecting South Africa. The ferrochrome industry in 
South Africa enlarged its capacity by 39 per cent from 2015, but had to operate at a lower capacity, as the utilisation of capacity dropped from 90 per cent in 2004 to 74 per cent in 2010 [7].

The market share of South African ferrochrome decreased from 50 per cent in 2001 to 42 per cent in 2010, while China increased from five per cent to 25 per cent during the same period; in 2011, the South African market share dropped to 36 per cent while China had 30 per cent [7]. Ferrochrome smelters create more jobs per ton exported than chrome ore from the mines, and it is expected that, if the beneficiation of ferrochrome stopped, South Africa's GDP would be negatively affected. In the current year,2021, owing to production challenges in China, the ferrochrome price is favouring South African producers, but it is more temporarily than sustainable.

Current processing technologies in ferrochrome production in South Africa include the Outotec process (used in most South African smelters), the Premus process (employed in Glencore Alloys), conventional furnaces (employed in both Glencore and Samancor smelters), and the DC arc furnace (employed in Samancor and Mogale Alloys). The cost involved in the above processes differs greatly in terms of energy efficiencies and reductants consumption. The DC arc and Premus technologies are more energy-efficient than Outotec and conventional furnaces. The Premus technology and DC arc furnaces consume fewer reductants than all the other technologies. Pre-reduction of ferrochrome pellets may improve the specific energy consumption efficiency of a closed submerged arc AC furnace to $2500 \mathrm{kWh} / \mathrm{t}$ and to $2000 \mathrm{kWh} / \mathrm{t}$ with an improvement on pre-reduction [8].

Environmental and safety considerations are very important aspects when choosing a ferrochrome processing technology. The major environmental consideration is to minimise emissions of fumes and dust particles from stacks and from the process of tapping in order to disallow the contamination of natural groundwater with toxic contaminants, and to minimise the liberation of carbon monoxide gas into the air [8]. In order to minimise such environmental issues, it is important to design or choose a better processing technology. Some of the options include selecting bigger closed energy-efficient furnaces, and using of carbon monoxide gas for preheating and for electricity cogeneration.

\subsection{Technologies for the future in ferrochrome processing}

\subsubsection{The use of methane as a reductant}

The ferroalloy industrial process is characterised by high emissions of carbon monoxide and energy consumption intensity, and its survival in the long term will be subject to radical change in the correct direction. In order to address the increasing cost of electricity, the use of methane/natural gas for completely reducing Ferro-alloys ores in solid state at lower temperatures than the known carbothermic reductions needs to be considered [9]. According to this author, the use of methane would be a good opportunity to change to a sustainable technology that could achieve the principles of the circular economy, with lower energy consumption and a reduced carbon footprint.

\subsubsection{The use of sodium hydroxide as a reductant}

With the discovery of ferrochrome ore in Canada, there was extensive research into less energy-intensive technologies to process ferrochrome more cheaply than current known processes. The choice of process technology comes with a challenge, owing to the high electricity selling price - a challenge that is experienced beyond South Africa. Natural Resource Canada, in response to this challenge, was mandated to give valuable support to innovate new technology for the direct reduction of ferrochrome ore using different fluxes or catalysts [10]. Part of the research has been into the success of caustic soda ( $\mathrm{NaOH})$ in direct reduction. The research work by Natural Resource Canada found that $\mathrm{NaOH}$, when added directly to ferrochrome ore at lower temperatures than those of smelting technologies, lead to increased reaction rates and a high level of metallisation.

\subsubsection{Using colemanite as flux material}

Fluxes are used in ferrochrome smelting to condition slag for its easy separation from metal, and to control the furnace condition. Chromite ores in South Africa are processed with the use of limestone and quartz for the addition of $\mathrm{CaO}$ and $\mathrm{SiO}_{2}$ to the process [11]. $\mathrm{CaO}$ helps with the ease of separation between the metal and the slag by ensuring that the slag flows, and $\mathrm{SiO}_{2}$ assists in lowering the melting point of the processed ore. Colemanite originates from Turkey, and has a molecular formula of $\mathrm{CaB}_{3} \mathrm{O}_{4}(\mathrm{OH})_{3} \cdot \mathrm{H} 2 \mathrm{O}_{2} \cdot \mathrm{B}_{2} \mathrm{O}_{3}$ [11]. It consists of both $\mathrm{SiO}_{2}$ and $\mathrm{CaO}$, and can be used in small quantities to flux chromite ore. Laboratory tests done in Mintek indicated that it is feasible to reduce processing temperatures in the ferrochrome smelting process from $1750^{\circ} \mathrm{C}$ to $1650^{\circ} \mathrm{C}$ by using colemanite instead of quartz and limestone [11]. The results indicated a similar amount and grate of metal alloy produced when using colemanite at $1650^{\circ} \mathrm{C}$ compared with smelting at $1750^{\circ} \mathrm{C}$ with quartz, magnesite and limestone. 


\subsubsection{Energy generation technology}

Ferrochrome smelting in South Africa uses a lot of electric energy, and so the industry needs to look at selfgenerated power to save costs and to reduce its carbon footprint. The world is in crisis: the demand for electricity continuously increases, but the generation capacity cannot meet the demand [12]. These authors suggest that the recovery of waste energy is of utmost importance to mitigate the energy crisis; and an opportunity to do this is present in the ferrochrome processing industry in the form of, off-gas thermal energy that is generated by the process. Furthermore, different methods and technologies for improving energy efficiency in the ferrochrome industry have been looked at, and the exploitation of off-gas thermal energy has recently been discussed. The smelting process produces an off-gas of carbon monoxide (mainly in closed furnaces) and carbon dioxide (mainly in open furnaces), which can be used to generate power through a power cogeneration plant. It is important for ferrochrome smelters to look into generating their own electricity.

\subsubsection{Preheating of fine ore in DC arc furnaces}

In the drive to reduce costs in the ferrochrome industry, the DC-arc furnace technology, founded on semiopen bath processing, was established. DC arc furnaces have increased power density with their ability to smelt fine feeds without following the agglomeration of ore fines process [13]. The disadvantage of a DC arc furnace is its energy loss, which is higher owing to heat loss from the sidewalls, because it is semiclosed process and requires a higher use of energy [13]. Furthermore, preheating of fines and fluxes to a temperature of $950^{\circ} \mathrm{C}$ before feeding them into the furnace will significantly minimise electrical energy requirements in a $D C$ arc furnace. The author emphasises the important point that the variation in temperature of the heated ore fines is kept below $10^{\circ} \mathrm{C}$ and that the variation in feed flow is kept below five per cent in order to achieve process stability and energy optimisation. Fluid bed technology has been designed for that purpose, and has adjustable fine ore mass flow and efficient heat transfer.

\subsubsection{Dissolution and reduction of chrome ore fines in ferrochromium slag}

Curr (in [14]) says that chromium contained in slag is in the shape of chromite ore particles, and that it is present in the slag stage in moderately reduced, melted, or not melted form, while the remainder is in the shape of alloy droplets that are confined to the slag. Oostuizyzen (in [14]) says that the three per cent to 15 per cent of chrome oxide present in ferrochromium slag in unreduced or partially reduced form encourages the need to treat the slag further for more chromium recovery.

In the study conducted by Kucukkaragoz and Eric [14], the dissolution of the chrome ore in the slag led to the concurrent reduction of iron oxide to $\mathrm{FeO}$ and then to $\mathrm{Fe}$, and of chrome oxide to $\mathrm{CrO}$ and then to $\mathrm{Cr}$. The $\mathrm{Fe}$ and $\mathrm{Cr}$ alloy was formed as metallic inside a graphite crucible [14]. Dissolution and reduction were both increasing with an increase in the basicity level of the slag, mainly in a reducing state of reaction. The results from this study showed that a significant amount of chromium and iron is recoverable from ferrochrome slags by using carbon reductants in conducive conditions, such as designing a technology with easy high-degree alloy settlement.

\subsubsection{Improving pellets' strength with the use of slag}

Ferrochrome production happens through a reduction reaction of a burden of chromium in a furnace. According to Hota et al. [15], good furnace efficiency, a good-quality ferrochrome, and the reduced consumption of reductants are largely determined by the quality of the burden. The burden is normally made of briquettes, lumpy ore, or sintered pellets. Most ferrochrome producers prefer sintered pellets because of their flexibility in composition, physical strength, control of slag chemistry, and better furnace efficiency. The strength of the sintered pellets is determined by a number of variables, including, type and amount of flux, heat transfer, moisture, temperature of sintering, and time taken for sintering [15].

\section{CONCEPTUAL METHOD AND THEORY FOR THE DEVELOPMENT OF THE TECHNOLOGY ROADMAP}

\subsection{Introduction of the conceptual model}

Technology roadmapping is an essential technique for any organisation to achieve and sustain its competitive advantage. The technology roadmap should form the basis of the organisation's strategy, which links to its vision and objectives because the business environment goes through cycles, changings continuously and quickly. Garcia and Bray (in [16]) say that technology roadmapping sketches a map of current and future products, markets, and technologies, recognising substitute markets and the technology routes for connections between markets, technologies, and products and the firm's objectives and resources.

Phaal et al. (in [17]) say that technology roadmaps have two parts: a roadmapping activity that indicates the stages and phases of the process; and the roadmapping outcome, which shows the multi-layered 
graphical structure that depicts the pace of change and significant time horizons by indicating identified time frames. Despeisse, Yang, Evans, Ford and Minshall [18] say that technology that is aligned with business model innovation is largely identified as the main enabler of a company's enhanced competitiveness and strengthened performance. These kinds of innovations need companies to imagine the future at the level of the company and the industry [18]. Roadmapping is a good instrument that can assist organisations to merge their management of technology with their strategic planning in order to build such imagined future. This section of the research proposes a conceptual framework for the development of a technology roadmap for ferrochrome producers in South Africa, taking into account the opportunities presented by the fourth industrial revolution technologies in the ferrochrome industry. A number of factors in a company, sector, or nation can trigger roadmapping; and there are several types of roadmapping, depending on the choice of the organisation. The roadmapping process is adaptable and scalable, and can be modified to match numerous innovation and strategic contexts [19]. However, such a process requires diligent design and planning, taking into consideration the structure of the roadmap, participation, and process. The conceptual method will consider the current challenges faced by ferrochrome producers, assess the current technology used by ferrochrome producers and, the technology that should be employed to meet the challenges, evaluate that technology, and develop a favourable technology roadmap.

Figure 1 summarises the conceptual method used to achieve the objectives of the research. It commences with the challenges faced by the South African ferrochrome industry. At the core of this model are the two research questions: How should ferrochrome smelters incorporate fourth industrial revolution technologies in order to improve their competitiveness? And what technology roadmap do SA ferrochrome producers need to follow to sustain their business? Sub-section 3.2 discusses the various components of this model in detail.

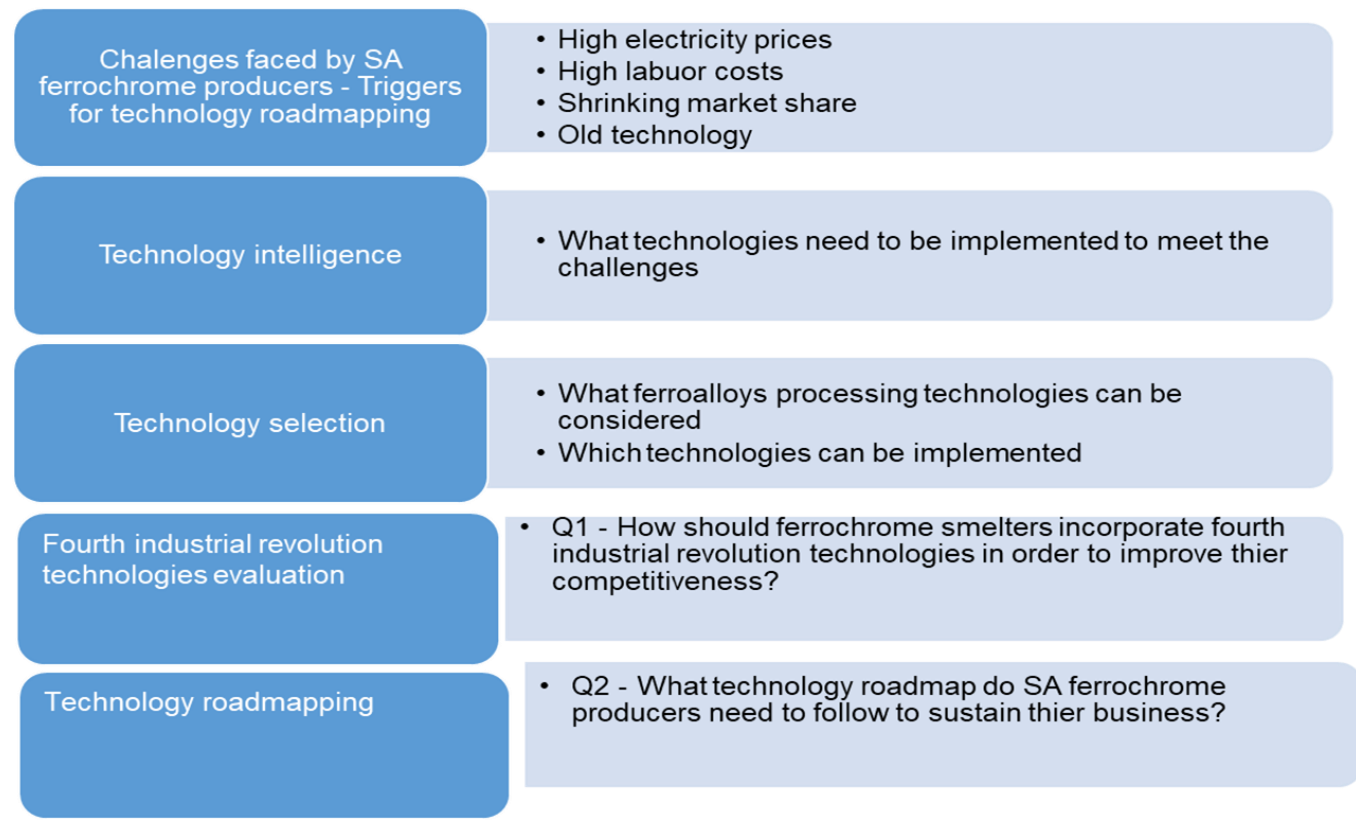

Figure 1: Conceptual method overview

\subsection{Discussion of the conceptual method}

\subsubsection{Triggers for technology roadmapping}

The South African ferrochrome industry is facing heavy competition from the Chinese and other ferrochrome markets. The price of ferrochrome metal has dropped to below operating cost for some ferrochrome producers in South Africa, making them unable to continue to produce ferrochrome. Increases in electricity, labour, and raw material costs have significantly increased the production cost of ferrochrome metals.

Suomalainen, Salo, Abrahamsson and Similä [20] say that the motive behind technology roadmaps is to create industry targets and to prepare for the future by recognising trends and making sound forecasts. Furthermore, the industry roadmap is said to be an incorporation of industrial challenges and technology forecasts. Thus, the motive behind industry roadmapping is to capture industry presuppositions that express a competitive environment and a technical thrust. DeGregorio (in [20]) says that roadmapping is done to 
envisage a forecast, that can address certain key areas, such as environmental threats, systems, platforms, capability, threats, and technology and business opportunities.

\subsubsection{Technologies selection}

The ferrochrome producers that are still in production need to assess the technologies they are currently using, and evaluate whether they will sustain or improve their competitive advantage. Technology assessment is the starting point of the concept of technology foresight.

Manufacturing industries have been using cutting-edge technologies for years. However, with recent manufacturing patterns such as Industry 4.0, and the Internet of Things, production systems will be disturbed. Selecting the correct technologies can produce exceptional competitive advantages: prompt responses to market changes, flexibility, enhanced ease of operation, improved productivity and quality, and increased customer satisfaction [21]. Singh and Sushil (in [21]) say that recognising the premier technology from a pool of options is a problem of selecting technology, and understanding how to solve such a challenge will aid an organisation in establishing efficient processes, more competitive services and products, and new solutions.

\subsubsection{Technology intelligence}

The ferrochrome industry needs to research technologies that will assist it to compete for market share in a way that achieves and sustains competitive advantage. Corporate investments in technology affect organisations and their performance, including their supply chains, the society, and their environment [22]. Farrukh and Holgado [22] add that, given the long-term effects of technologies, initiating sustainability thinking at the initial stages of assessment is not just relevant but crucial. Business context and technology have a powerful effect on an organisation's environmental, economic, and social impacts; thus the timely consideration of the social and environmental aspects and their integration into innovation and new technology development is vital. This aligns with the motive for a sustainability vision that underlies a roadmap and gives guidance on organisational priorities, resource allocation, technology development, and business model designs to identify business practices and strategies that contribute to the sustainability of the organisation's value [22].

\subsubsection{Fourth industrial revolution technologies evaluation}

The technologies discovered through technology intelligence need to be evaluated for their feasibility and success in the ferrochrome industry. Digitisation needs to be incorporated into new technologies to align the South African ferrochrome industry with the fourth industrial revolution. Valencia, Lamouri, Pellerin, Dubois and Moeuf [23] say that the manufacturing world is moving through an organisational and technological transformation as a result of the fourth industrial revolution. The market trends revealed in such an environment includes a great variety in products and services, a reduction in processing units, satisfactory standards of timeous delivery, high labour costs, and customisation [23]. Recently, matters of digitisation such as Industry 4.0, Big Data, Smart Something, artificial intelligence, and the Internet of Things receive much attention, and such expanding trends lead to the digitisation and sharing of products and value chains that lead to greater ability to achieve and increase competitiveness in the manufacturing sector.

\subsubsection{Technology roadmapping}

Roadmapping, whether strategic, business, product, or technology-related, is a method that has been established in industrial engineering, and its development is being pioneered by practitioners rather than academics [24]. According to Kerr and Phaal [24], in the evolution of roadmapping, six organisations can be credited with the development of roadmapping: BP, Motorola, EIRMA, Semiconductor Industry Association, Lucent Technologies, and Phillips. These organisations developed the acknowledged body of knowledge for the current procedure of roadmapping, and were dominant in its subsequent adoption by other firms and its increased attractiveness to researchers. This history presents an opportunity to draw attention to such seminal projects, and to re-assess and reaffirm the flexibility and capability of roadmapping when it was being developed as a unique tool/method in the sphere of innovation and technology management [24].

Zhang, Robinson, Porter, Zhu, Zhang and Lu [25] say that, since Corning and Motorola first applied technology roadmaps to technology evolution, commercial strategy, and positioning studies, technology roadmaps have become a robust instrument for strategic planning. Phaal et al. (in [25]) say that technology roadmapping is key in traversing the dynamic association between the changing environment, organisational objectives, and technological resources. 
The development of a suitable roadmap is the ultimate objective of this research study. Through online qualitative interviews, different respondents involved with ferrochrome production participated in providing intelligence and in choosing suitable technologies that would enhance productivity, reduce costs, and restore and improve South Africa's ferrochrome metal market share in the global industry. These respondents from the ferrochrome industry, about 40 in total, were in senior positions (engineers, superintendents, and managers) in technical, engineering, production, or research and development departments, and they all had a good knowledge of ferrochrome production and the industry landscape. Twelve ferrochrome smelters were still active in the production of ferrochrome, and formed the sampling units for this study.

The data obtained through interviews was edited, coded, classified, and tabulated in accordance with the objective of developing a technology roadmap. The content analysis method of analysing qualitative data was used to analyse the collected data in order to show the prioritised technologies and the research that would be required in the short, medium, and long term on a 30-year timeline.

\section{RESULTS AND DISCUSSION}

All participating ferrochrome producers agreed that a technology roadmap for ferrochrome production is essential, with 87 per cent of them being in favour of high automation in ferrochrome production processes. Automation responds to the labour challenges of high costs, safety, and unrest as a challenge for the industry, mentioned by 55.2 per cent of the respondents. The reasons for considering the development of a technology roadmap for ferrochrome smelters are summarised as better planning, business success, production cost reduction (labour and electricity), adaptation to market changes, market uncertainty, improvement of safety, introduction of new technologies, increased competition (China is the biggest producer of ferrochrome), and sustainability.

Most industry players were concerned about implementing a new technology that would enable energysaving in the face of high electricity costs in the industry. About 89 per cent of the respondents agreed with the use of solar energy, where applicable, to save energy; 100 per cent agreed with the use of effluence gas for power generation; and 96 per cent agreed with the use of effluence gas as a source of heat energy for use in the ferrochrome processes. The industry players were not sure about the use of colemanite as a reflux because an energy saving initiative such as colemanite is not in use in South Africa. Only 13 per cent of respondents had knowledge of and support for this technology. For the energy-saving technology of 'dissolution and reduction of chrome ore fines in slag', 48 per cent of the respondents had knowledge of and supported such technology. About 41 per cent of the respondents supported preheating fine ore before smelting in DC arc furnaces as an energy-saving technology.

The availability and cost of reductants was mentioned by 22 per cent of the participants when responding to the current and future profitability challenges facing the ferrochrome industry. Most did not agree with the use of sodium hydroxide and methane gas as reductants, with only 13 and 14 per cent respectively in favour of this technology. However, it was apparent during the interviews that most industry players were not familiar with this technology. This would have an influence on the timing of the introduction of this technology in the proposed technology roadmap.

Responses to a market analysis of the demand for ferrochrome showed that the industry players were positive about the continued demand for ferrochrome. Only 30 per cent of the respondents predicted that the demand would shrink over the next 10, 20, and 30 years. About 71 per cent of the participating industry players thought that the technology currently used by South African ferrochrome producers would not sustain continued production in the industry.

The reasons highlighted by the industry for the non-sustainability of the current technologies included labour-intensive technologies, high electricity consumption and costs, carbon tax, high labour costs, and a lack of digital technology. The industry players were also in favour of high automation and process streamlining, with 87 per cent and 86 per cent of the respondents respectively agreeing with the implementation of such technologies. The industry players also mentioned that the fourth industrial revolution would have a significant impact on the production of ferrochrome in reducing the labour force while eliminating safety risks through artificial intelligence and machine learning. 
The anticipated improvements included increased productivity, competitiveness, ease of access to information, better control and monitoring systems, and increased efficiency of operations. When identifying technologies that could be used by the industry to meet current and future challenges, 50 per cent of the respondents mentioned technologies related to the fourth industrial revolution (e.g., artificial intelligence, robotics, and high automation). The suggested digitisation solutions included the use of data for predictive maintenance models, digitised payroll systems, remote control of equipment, process control predictive models, and real-time information processing.

Table 1 shows the most often identified triggers for technology roadmapping, along with other triggers mentioned by the industry players for the respective technology solutions. Some of the technologies, such as artificial intelligence, automation, and machine learning, were suggested as solutions to multiple challenges/triggers. A synthesis of the qualitative interview results resulted in a technology roadmap for the ferrochrome industry (Figure 2).

A careful interpretation of the results of this study identified three phases of technology roadmap over a 30-year period. Most digitisation should be deferred to the second phase of the roadmap because it has the potential to disrupt the industry, as happened with failed mechanisation at the Lonmin mine in South Africa [26]. The digitisation technologies that were prioritised in this roadmap were remote process technologies, advanced predictive maintenance systems, real-time data and information processing, predictive modelling through machine learning, cloud connectivity, and digital health and safety systems.

Table 1: Roadmap triggers and suggested technologies

\begin{tabular}{|c|c|}
\hline Identified triggers & Technology solutions \\
\hline $\begin{array}{l}\text { Reduction of production costs } \\
\text { (electricity costs) }\end{array}$ & $\begin{array}{l}\text { - Co-generation of power from effluent gas } \\
\text { - Use of effluent gas as source of heat energy } \\
\text { - Use of solar energy } \\
\text { - Preheating of fine ore before feeding into a DC arc furnace } \\
\text { - Use of colemanite as a flux } \\
\text { - Dissolution and reduction of chrome ore fines into slag }\end{array}$ \\
\hline $\begin{array}{l}\text { Reduction of production costs } \\
\text { (labour costs) }\end{array}$ & $\begin{array}{l}\text { - High automation } \\
\text { - Al } \\
\text { - Machine learning } \\
\text { - Digitisation } \\
\text { - Process streamlining }\end{array}$ \\
\hline - $\quad$ Changes in technology & $\begin{array}{l}\text { - High automation } \\
\text { - Al } \\
\text { - Machine learning } \\
\text { - Digitisation }\end{array}$ \\
\hline - $\quad$ Market uncertainty & - Steel production technology \\
\hline - Carbon tax & $\begin{array}{l}\text { - Use of low carbon-containing reductants (methane gas and } \\
\text { sodium hydroxide) } \\
\text { - Effluent gas treatment and recycling } \\
\text { - Renewable energy sources }\end{array}$ \\
\hline $\begin{array}{l}\text { Raw material availability and cost } \\
\text { owing to export of raw materials }\end{array}$ & - Process control - efficient processes \\
\hline - $\quad$ Export costs & - Steel production and steel products \\
\hline
\end{tabular}

There was a concern that increased digitisation would lead to even more power consumption - a situation that is undesirable for the South African ferrochrome industry. Lange, Pohl and Santarius [27] postulated two main situations in which digitisation would be likely to lead to increased energy consumption: the direct effect on energy consumption observed from the production, usage, and disposal of information and communication technologies; and when there is economic growth from increased labour and energy productivity. The latter applies to the ferrochrome industry.

Taking into account the challenge of increasing electricity costs for ferrochrome producers in South Africa, and the potential increase in energy consumption with the adoption of digitisation, an obvious short-term solution for the industry is to tackle the issue of energy cost. This has led to the first phase of the ferrochrome industry technology roadmap being termed 'stabilisation' (see Figure 2). During this phase, various alternative energy sources are considered to supplement the power supply from the grid. These include the co-generation of power from effluent gases, the use of effluent gas as a source of heat energy, and the use of solar energy. This energy mix recognises that none of these energy sources individually has reached the maturity of being a sole replacement for the electricity grid. 
The use of clean energy sources such as solar positively contributes to stabilisation, as long-term investors are increasingly demanding a reduced carbon footprint in the portfolio of companies in which they have invested [28]. During a third phase of sustainability, improved steel technology is realised, a digitised ferrochrome smelting process is optimised to be more efficient, and renewable energy sources with more technology maturity become a more dominant source of energy. In order to develop internal capacity and to build the necessary technology intelligence, each effort to deploy alternative technologies is preceded by thorough research. In some cases, deployment and research activities take place concurrently (e.g., the use of colemanite as a flux, and the dissolution and reduction of chrome ore fines into slag).

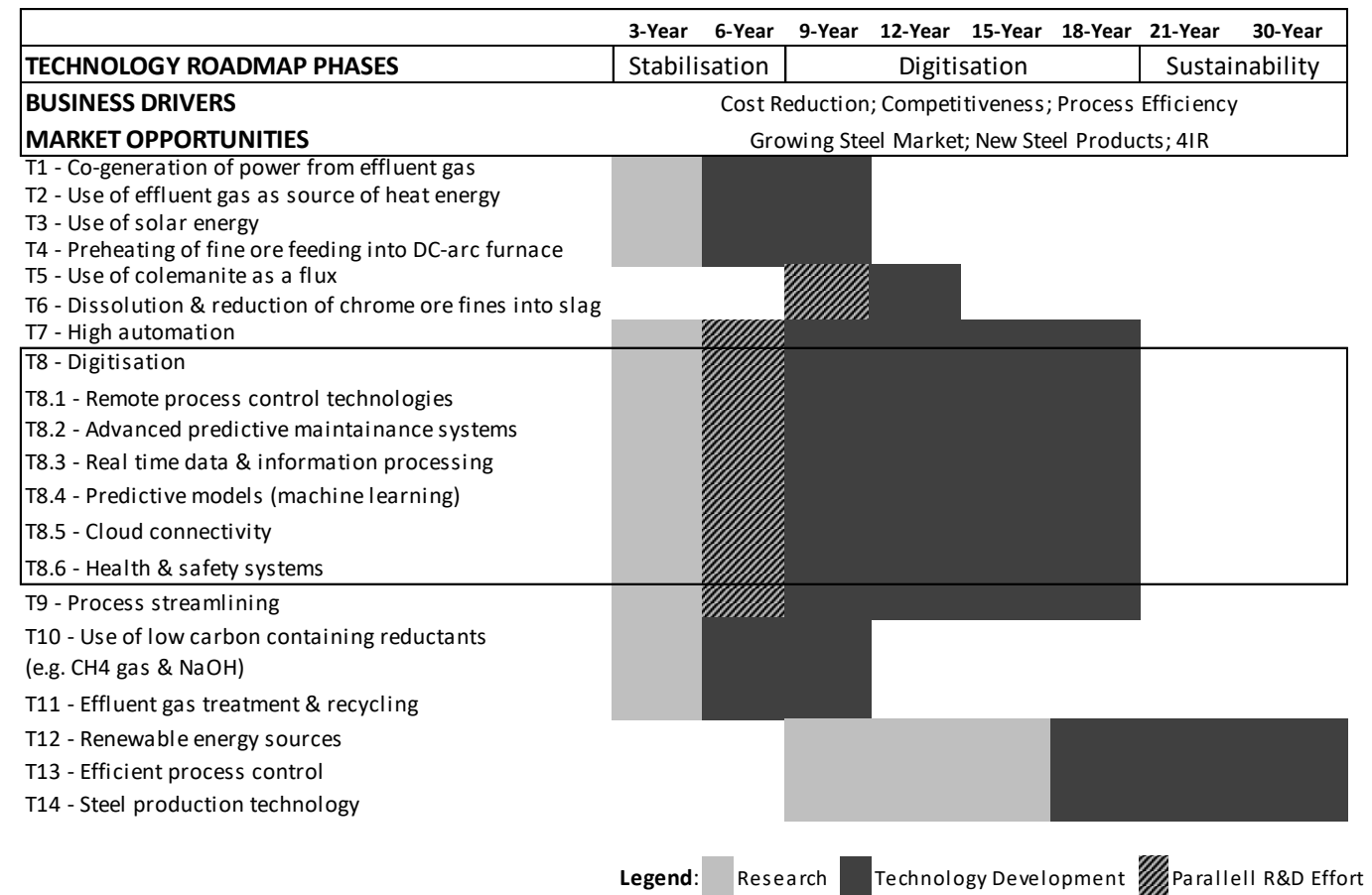

Figure 2: Suggested South African ferrochrome producers' technology roadmap

\section{CONCLUSIONS AND RECOMMENDATIONS}

In the South African context of increasing electricity prices and increasing competition from China for the ferrochrome industry, the objective of this research was to formulate a technology roadmap that could assist the South African ferrochrome industry in sustaining ferrochrome production and reclaiming its high market share from Chinese ferrochrome producers. The 30-year roadmap that was developed, with inputs from ferrochrome industry respondents, shows various technology options that are phased in the short, medium, and long term.

This research has also investigated the possibility of such a technology roadmap incorporating fourth industrial revolution technologies. Taking into account the ferrochrome industry's scepticism about investment in new technologies as a result of market uncertainty, with China controlling the ferrochrome market, the roadmap is divided into the three phases of stabilisation, digitisation, and sustainability. This is a unique managerial and theoretical contribution to the incorporation of fourth industrial revolution technologies into industries with underlying challenges. The stabilisation phase addresses existing issues, such as the high electricity cost, by introducing alternative energy sources. Once the industry has been stabilised, full-scale digitisation is introduced. The sustainability phase allows the industry to pioneer major challenges such as stand-alone off-grid solutions through renewable energy, process efficiency, and the introduction of new steel production technologies.

This research has not been done before in the ferrochrome industry of South Africa. Technology roadmapping, which incorporates the fourth industrial revolution technologies in a sustainable form, is needed by the ferrochrome industry as well as by most other industries. It is recommended that this research be expanded to other industries in order to develop a model for the incorporation of fourth industrial revolution technologies that is not dependent on a specific industry or country conditions. 


\section{REFERENCES}

[1] Holappa, L. 2013. Basics of ferroalloys. In Gasik, M., Handbook of Ferroalloys, 12 ${ }^{\text {th }}$ ed, Elsevier., 9-28.

[2] Daim, T.U., Meissner, D. \& Carayannis, E. 2019. Roadmapping for engineering and technology management. Journal of Engineering and Technology Management, 1, 1-2.

[3] Phaal, R. 2004. Technology roadmapping: A planning framework for evolution and revolution. Technological Forecasting and Social Change, 71(1-2), 5-26.

[4] Carvalho, M.M., Fleury, A. \& Lopes, A.P. 2013. An overview of the literature on technology roadmapping (TRM): Contributions and trends. Technological Forecasting and Social Change, 80(7), 1418-1437.

[5] Steenkamp, J.D., Bam, W.G., Ringdalen, E., Mushwana, M., Hockaday, S.A.C. \& Sithole, N.A. 2018. Working towards an increase in manganese ferroalloy production in South Africa: A research agenda. Journal of the Southern African Institute of Mining and Metallurgy, 118(6), 645-654.

[6] Van der Lingen, E. \& Paton, A. 2018. Market implications for technology acquisition modes in the South African ferrochrome context. Journal of the Southern African Institute of Mining and Metallurgy, 118(10), $1087-1094$.

[7] XSTRATA. 2011. Maximising South Africa's chrome ore endowment to create jobs and drive sustainable growth. Chrome Ore Brochure, [Online] Available at: https: / /www.portsregulator.org/images/documents/XSTRATA_submission-Ferrochrome_Industry_ Communique.pdf [Accessed 14 Apr-2021].

[8] Basson, J. \& Daavittila, J. 2013. High carbon ferrochrome technology. In Gasik, M., Handbook of Ferroalloys, $12^{\text {th }}$ ed, Elsevier., 317 - 363.

[9] Eric, R.H. 2018. Sustainability and circular economy: Why and how for ferro-alloy manufacturing. Proceedings of International Ferro-Alloys Congress, Cape Town.

[10] Sokhanvaran, S., Paktunc, D. \& Barnes, A. 2018. NaOH-assisted direct reduction of ring of fire chromite ores, and the associated implications for processing. Journal of the Southern African Institute of Mining and Metallurgy, 118(6), 581-588.

[11] Erwee, M.W., Geldenhuys, I.J., Sitefane, M.B. \& Masipa, M. 2018. Fluxing of South African chromite ore with colemanite. Journal of the Southern African Institute of Mining and Metallurgy, 118(6), 661-670.

[12] Zhang, L., Chennells, M. \& Xia, X. 2018. A power dispatch model for a ferrochrome plant heat recovery cogeneration system. Applied Energy, 227, 180-189.

[13] Weber, P. 2018. State of the art ore pre-heating with fluid-bed technology and innovative furnace feeding. Proceedings of International Ferro-Alloys Congress, Cape Town.

[14] Kucukkaragoz, C.S. \& Eric, R.H. 2018. Dissolution and reduction of chromite ore in ferrochromium slags. Proceedings of $15^{\text {th }}$ INFACON, Cape Town, South Africa.

[15] Hota, S.K., Das, K., Reddy, A.S. \& Kumar, A. 2018. A new approach to improve the strength of chromite pellets. Proceedings of International Ferro-Alloys Congress, Cape Town.

[16] Battistella, C., De Toni, A.F. \& Pillon, R. 2015. The extended map methodology: Technology roadmapping for SMES clusters. Journal of Engineering and Technology Management, 38, 1-23.

[17] Ghazinoory, S., Dastranj, N., Saghafi, F., Kulshreshtha, A. \& Hasanzadeh, A. 2017. Technology roadmapping architecture based on technological learning: Case study of social banking in Iran. Technological Forecasting and Social Change, 122, 231-242.

[18] Despeisse, M., Yang, M., Evans, S., Ford, S. \& Minshall, T. 2017. Sustainable value roadmapping framework for additive manufacturing. Procedia CIRP, 61, 594-599.

[19] Phaal, R. \& Muller, G. 2009. An architectural framework for roadmapping: Towards visual strategy. Technological Forecasting and Social Change, 76(1), 39-49.

[20] Suomalainen, T., Salo, O., Abrahamsson, P. \& Similä, J. 2011. Software product roadmapping in a volatile business environment. Journal of Systems and Software, 84(6), 958-975.

[21] Hamzeh, R. \& Xu, X. 2019. Technology selection methods and applications in manufacturing: A review from 1990 to 2017. Computers \& Industrial Engineering, 138, 106-123.

[22] Farrukh, C. \& Holgado, M. 2020. Integrating sustainable value thinking into technology forecasting: A configurable toolset for early stage technology assessment. Technological Forecasting and Social Change, 158, 1 -15.

[23] Valencia, E.T., Lamouri, S., Pellerin, R., Dubois, P. \& Moeuf, A. 2019. Production planning in the fourth industrial revolution: A literature review. IFAC-PapersOnLine, 52(13), 2158-2163.

[24] Kerr, C. \& Phaal, R. 2020. Technology roadmapping: Industrial roots, forgotten history and unknown origins. Technological Forecasting and Social Change, 155, 1-16.

[25] Zhang, Y., Robinson, D.K., Porter, A.L., Zhu, D., Zhang, G. \& Lu, J. 2016. Technology roadmapping for competitive technical intelligence. Technological Forecasting and Social Change, 110, 175-186.

[26] Stewart, P. 2015. Accelerated mechanisation and the demise of a mass-based labour force? Platinum mines in South Africa. Review of African Political Economy, 42(146), 633-642.

[27] Lange, S., Pohl, J. \& Santarius, T. 2020. Digitalization and energy consumption. Does ICT reduce energy demand? Ecological Economics, 176, 1-14.

[28] Eccles, R.G. \& Klimenko, S. 2019. The investor revolution. Harvard Business Review, May-June, 106 - 116, [Online] Available at: https://hbr.org/2019/05/the-investor-revolution [Accessed 12 Sep-2020].

[28] FerroAlloyNet.com. 2019. 2014-2018 chrome industry data analysis report. Published 2 April 2019. 